\title{
Blocking the short isoform of augmenter of liver regeneration inhibits proliferation of human multiple myeloma U266 cells via the MAPK/STAT3/cell cycle signaling pathway
}

\author{
WENQI HUANG ${ }^{1,2}$, HANG SUN ${ }^{1}$, TING HU ${ }^{1}$, DONGJU ZHU ${ }^{3,4}$, XIANLI LONG ${ }^{1}$, HUI GUO ${ }^{1}$ and QI LIU ${ }^{1}$ \\ ${ }^{1}$ Key Laboratory of Molecular Biology for Infectious Diseases (Ministry of Education), \\ Department of Infectious Diseases, Institute for Viral Hepatitis, ${ }^{2}$ Department of Intensive Care Medicine, \\ The Second Affiliated Hospital of Chongqing Medical University, Chongqing 400010; ${ }^{3}$ Department of Nephrology, \\ The Affiliated Hospital of Panzhihua University, Panzhihua, Sichuan 617000; ${ }^{4}$ Department of Nephrology, \\ The Second Affiliated Hospital of Chongqing Medical University, Chongqing 400010, P.R. China
}

Received April 29, 2020; Accepted November 20, 2020

DOI: $10.3892 / 01.2021 .12458$

\begin{abstract}
Multiple myeloma (MM) is the second most common haematological malignancy and remains an incurable disease, with most patients relapsing and requiring further treatment. Augmenter of liver regeneration (ALR) is a vital protein affecting fundamental processes such as energy transduction, cell survival and regeneration. Silencing ALR inhibits cell proliferation and triggers apoptosis in human MM U266 cells. However, little is known about the role of $15-\mathrm{kDa}-A L R$ on MM. In the present study, the role of $15-\mathrm{kDa}-\mathrm{ALR}$ in human MM cells was investigated. Blocking extracellular 15-kDa-ALR with an anti-ALR monoclonal antibody $(\mathrm{McAb})$ decreased the proliferation and viability of U266 cells. However, the results of flow cytometry revealed no changes in apoptosis, and the expression levels of Bax, Bcl-2, caspase-3 and cleaved caspase-3 were not affected. However, combined treatment with anti-ALR McAb and epirubicin increased the apoptosis of U266 cells. RNA sequencing results indicated that the ERK1/2, JNK-MAPK and STAT3 signaling pathways, as well as the cell cycle, were associated with the mechanism of action of the anti-ALR $\mathrm{McAb}$, and PCR, western blotting and cell cycle analysis confirmed these results. The present findings suggested that blocking extracellular 15-kDa-ALR in U266 cells with an
\end{abstract}

Correspondence to: Professor Qi Liu, Key Laboratory of Molecular Biology for Infectious Diseases (Ministry of Education), Department of Infectious Diseases, Institute for Viral Hepatitis, The Second Affiliated Hospital of Chongqing Medical University, 76 Linjiang Road, Chongqing 400010, P.R. China

E-mail: 300610@hospital.cqmu.edu.cn

Abbreviations: ALR, augmenter of liver regeneration; MM, multiple myeloma; McAb, monoclonal antibody; GO, Gene Ontology

Key words: ALR, MM cells, proliferation, $\mathrm{McAb}$
anti-ALR McAb decreased cell proliferation via the MAPK, STAT3 and cell cycle signaling pathways without increasing apoptosis. Thus, 15-kDa-ALR may be a new therapeutic target for myeloma.

\section{Introduction}

Multiple myeloma (MM) accounts for $\sim 13 \%$ of hematological cancers, with an estimated 24,280 to 30,330 new cases and 12,650 deaths in 2016 (1), and patients survive an average of 3 years (2). Although modern combination therapies induce rapid, deep and sustainable responses, as well as prolonging survival (3), MM remains an incurable disease, and the majority of patients relapses and requires further treatment (4). Thus, novel targets for treating MM are urgently required.

Augmenter of liver regeneration (ALR), also known as GFER, is a vital protein in various biological processes that was first identified by Hagiya et al (5). ALR occurs in two isoforms: A long form comprising 205 amino acid residues with a molecular weight of $23 \mathrm{kDa}(6)$ that is present in the intermembrane space of mitochondria (7), and a short form consisting of 125 amino acids with a molecular weight of $15 \mathrm{kDa}(8)$ that is secreted by hepatocytes and is present in serum (9). Accumulating evidence has revealed that ALR affects fundamental processes such as energy transduction (10), cell survival, cell regeneration (11), metabolic homeostasis, iron metabolism (12) and stem cell maintenance (13). Different isoforms of ALR have been associated with different subcellular locations and therefore specific functions (14), but despite considerable research on the overexpression and inhibition of 23- and 15-kDa-ALR, their specific functions remain unclear.

A previous study has demonstrated that silencing ALR can influence proliferation and apoptosis in human MM U266 cells (15). However, little is known about the role of 15-kDa-ALR in MM. Therefore, the present study aimed to investigate the role and mechanism of extracellular 15-kDa-ALR in MM. 


\section{Materials and methods}

Preparation of anti-ALR monoclonal antibody. The 15-kDa-recombinant human ALR (rhALR) protein was purchased from Abcam. A total of 5 female BALB/c mice (age, 6-10 weeks old; weight, 20-25 g) were obtained from the Experimental Animal Center of Chongqing Medical University (Chongqing, China). All mice received humane treatment according to the regulations of the Institutional Animal Care and Use Committee of Chongqing Medical University. All mice were housed in a specific pathogen-free laboratory in an acclimatized room at standard room conditions $\left(25 \pm 2^{\circ}\right.$ and $55 \%$ humidity), with a 12 -h light/dark cycle. Mice were allowed free access to water and standard chow. The rhALR protein was injected subcutaneously into five BALB/c mice for immunization. Subsequently, anti-ALR monoclonal antibody (McAb) was prepared using hybridoma technology as previously described (16). Splenocytes were harvested and fused with myeloma SP2/0 cells (obtained from the Institute of Viral Hepatitis of Chongqing Medical University) to generate hybridoma cells, which were cultured in RPMI-1640 medium (Gibco; Thermo Fisher Scientific, Inc.) supplemented with 20\% FBS (HyClone; Cytiva) and $100 \mathrm{U} / \mathrm{ml}$ penicillin and streptomycin at $37^{\circ} \mathrm{C}$ in a humidified atmosphere with $5 \% \mathrm{CO}_{2}$. Single antibody-producing hybridoma cells were isolated using the limiting dilution technique, and supernatants of growth-positive wells were aspirated and screened for the presence of antibodies using ELISA. The ratio of the absorbance of hybridoma cell culture supernatants and myeloma cell SP2/0 culture supernatants was measured at $450 \mathrm{~nm}$. Absorbance $>1.5$ at optical density (OD) $450 \mathrm{~nm}$ and ratio of the absorbance of hybridoma cell culture supernatants to that of negative controls $>2.1$ were considered positive. Single McAb-producing hybridoma cells were isolated and were injected intraperitoneally into ten $\mathrm{BALB} / \mathrm{c}$ mice to produce ascites for large-scale McAb production. All mice were anesthetized using 3\% isoflurane and sacrificed by cervical dislocation 10-14 days after injection. Ascitic fluid containing $\mathrm{McAb}$ was harvested from the intraperitoneal cavity using a $21-\mathrm{G}$ needle and centrifuged at $10,000 \mathrm{x}$ g at $4^{\circ} \mathrm{C}$ for $10 \mathrm{~min}$. Isotypes of McAb were detected using IsoQuick strips (Roche Molecular Diagnostics). Negative hybridoma cells were also prepared as negative control ascites. HiTrap ${ }^{\mathrm{TM}}$ IgM Purification HP (GE Healthcare Life Sciences) was used to purify the monoclonal IgM according to the manufacturer's protocol.

ELISA. For ELISA, 96-well plates were coated with 15-kDa-rhALR $(4 \mu \mathrm{g} / \mathrm{ml})$ in $100 \mu \mathrm{l}$ coating buffer overnight at $4^{\circ} \mathrm{C}$ and incubated with blocking solution, consisting of 3\% BSA (Beijing Solarbio Science \& Technology Co., Ltd.) in $0.05 \%$ Tween-20-PBS (PBST) solution, at $4^{\circ} \mathrm{C}$ overnight. Ascites were diluted at the ratio of 1:100, 1:1,000, 1:10,000, 1:100,000 and 1:1,000,000. After washing with PBST, $100 \mu 1$ ascites diluted at different ratios were added and incubated at $4^{\circ} \mathrm{C}$ overnight. After incubation, the plates were washed three times with PBST, and $100 \mu 1$ 1:10,000-diluted HRP-conjugated goat anti-mouse immunoglobulin (cat. no. 7076P2; Cell Signaling Technology, Inc.) was added to each well and incubated for $1 \mathrm{~h}$ at room temperature. After washing three times with PBST, the enzymatic activity was determined by adding $100 \mu 13,3$ ',5,5'-tetramethylbenzidine substrate solution and incubating in the dark at $37^{\circ} \mathrm{C}$ for $30 \mathrm{~min}$, followed by adding $5 \mu \mathrm{l} 2 \mathrm{M}$ sulfuric acid per well to terminate the reaction. The absorbance was recorded at $450 \mathrm{~nm}$ using a microplate reader. For detecting ALR protein in the medium, U266, RPMI8226 and MM1.S cells were cultured in serum-free medium at $37^{\circ} \mathrm{C}$ for $48 \mathrm{~h}$, and 96-well plates were coated with cell medium and serial dilutions of rhALR protein $(2,000,1,000,500,250,125$, $62.5,31.25$ and $0 \mathrm{ng} / \mathrm{ml}$ ). The quantity of protein was calculated by the standard curve.

Cell culture and treatment. The human MM U266, RPMI8226 and MM1.S cell lines were obtained from the Institute of Viral Hepatitis of Chongqing Medical University. U266 and MM1.S cells were cultured in RPMI-1640 medium (Gibco; Thermo Fisher Scientific, Inc.) supplemented with 10\% FBS (HyClone; Cytiva) and $100 \mathrm{U} / \mathrm{ml}$ penicillin and streptomycin (Invitrogen; Thermo Fisher Scientific, Inc.). RPMI8226 cells were cultured in Iscove's modified Dulbecco's medium (Gibco; Thermo Fisher Scientific, Inc.) supplemented with 20\% FBS and $100 \mathrm{U} / \mathrm{ml}$ penicillin and streptomycin. Cells were grown at $37^{\circ} \mathrm{C}$ in a humidified atmosphere with $5 \% \mathrm{CO}_{2}$. Ascites containing anti-ALR McAb were added to the medium as the treatment group, while ascites produced by negative hybridoma cells constituted the negative control group, and PBS was used for the blank group.

Cell viability assay. Different dilutions of ascites containing anti-ALR McAb (1:10, 1:50 and 1:100), negative ascites and PBS were incubated with U266 cells for different time periods (24, 48 and 72 h). A Cell Counting Kit-8 (CCK-8; Beijing Solarbio Science \& Technology Co., Ltd.) assay was used to determine the cell survival rate according to the manufacturer's protocol. Cells were plated in 96-well plates at a density of $1 \times 10^{4}$ cells/well. After culturing at $37^{\circ} \mathrm{C}$ for 24,48 or $72 \mathrm{~h}$, the quantity of viable cells was measured. A total of $10 \mu \mathrm{l} \mathrm{CCK}-8$ reagent was added to each well and incubated at $37^{\circ} \mathrm{C}$ for $2 \mathrm{~h}$. The absorbance was recorded at $450 \mathrm{~nm}$ using a microplate reader, and the following formula was used to calculate cell viability: Cell viability $(\%)=[\mathrm{A}$ (ascites) A (Blank)] / [A (0 dosing) - A (blank)] x 100.

Apoptosis analysis via flow cytometry. The apoptosis rates of human MM cells treated with anti-ALR McAb, negative ascites and PBS were determined using an Annexin V-FITC/PI staining kit (BD Biosciences). Cells were washed twice with cold PBS and resuspended in $1 \mathrm{X}$ binding buffer at a cell density of $1 \times 10^{6}$ cells $/ \mathrm{ml}$. Cells were incubated with $5 \mu 1$ FITC and $10 \mu \mathrm{l}$ PI for $15 \mathrm{~min}$ at room temperature in the dark. A total of $1 \times 10^{4}$ cells were recorded by the FACSCanto II flow cytometer (BD Biosciences) for each sample. Fluorescence data were measured and analysed using FACSCanto II software (BD Biosciences). Apoptosis detection in the presence of injury factors was the same as aforementioned. Ascites containing anti-ALR McAb, negative ascites and PBS were incubated with U266 cells at the concentration of 1:10 for $48 \mathrm{~h}$. Subsequently, $0.004 \mathrm{mg} / \mathrm{ml}$ epirubicin (Pfizer, Inc.) was added to the medium for $24 \mathrm{~h}$ at $37^{\circ} \mathrm{C}$. Cells were harvested for apoptosis analysis. A cell cycle and apoptosis analysis kit 
(Beijing Solarbio Science \& Technology Co., Ltd.) was used to determine the cell cycle according to the manufacturer's protocol. U266 cells were treated with anti-ALR McAb, negative ascites and PBS at a concentration of 1:10. After culturing at $37^{\circ} \mathrm{C}$ for $72 \mathrm{~h}$, cells were harvested and washed with PBS, then fixed with $70 \%$ ethanol at $4^{\circ} \mathrm{C}$ for $2 \mathrm{~h}$. A total of $100 \mu \mathrm{l}$ RNase A was added for $30 \mathrm{~min}$ at $37^{\circ} \mathrm{C}$, then PI $(0.5 \mathrm{ml})$ was added and incubated for $10 \mathrm{~min}$ at $4^{\circ} \mathrm{C}$ in the dark for staining. Next, cells were assessed using a FACSCanto II flow cytometer (BD Biosciences). Cell cycle was analyzed using ModFit LT software (version 3.2; Verity Software House, Inc.).

Western blotting. Proteins were extracted from cells using RIPA lysis buffer (Beyotime Institute of Biotechnology) and quantified using a BCA kit (Beyotime Institute of Biotechnology). Proteins (60 $\mu \mathrm{g} /$ lane) were separated via 15\% SDS-PAGE, transferred to polyvinylidene fluoride membranes, blocked with 5\% skimmed milk in TBS for $1 \mathrm{~h}$ at $37^{\circ}$ and then incubated overnight at $4^{\circ} \mathrm{C}$ with primary antibodies. The primary antibodies and dilutions used were as follows: Anti-Bax (1:1,000; cat. no. 2774S), anti-Bcl-2 (1:1,000; cat. no. 4223T), anti-caspase-3 (1:1,000; cat. no. 9662S), anti-cleaved caspase-3 (1:1,000; cat. no. 9661T), anti-p44/42 (1:1,000; cat. no. 4695T), anti-phospho-p44/42 (1:1,000; cat. no. 4377T), anti-p38 (1:1,000; cat. no. 8690T), anti-phospho-p38 (1:1,000; cat. no. 4511T), anti-JNK (1:1,000; cat. no. 9252T), anti-phospho-JNK (1:1,000; cat. no. 9251S), anti-STAT3 (1:1,000; cat. no. 4904T), anti-phospho-STAT3 (1:1,000; cat. no. 9145T) and anti- $\beta$-actin (1:1,000; cat. no. 4970T), all from Cell Signaling Technology, Inc. Anti- $\beta$-tubulin $(1: 1,000$; cat. no. 102053-T34) was purchased from Sino Biological, Inc. Anti-CDK1 (1:1,000; cat. no. ab201008) and anti-cyclin D1 (1:1,000; cat. no. ab40754) were obtained from Abcam. After incubation for $1 \mathrm{~h}$ at $37^{\circ} \mathrm{C}$ with HRP-conjugated secondary antibodies $(1: 10,000$; cat. no. 7074P2; Cell Signaling Technology, Inc.), the protein bands were visualized using an enhanced chemiluminescence kit (Nanjing KeyGen Biotech Co., Ltd.) to detect immunoreactive bands with a ChemiDoc Imaging System (Bio-Rad Laboratories, Inc). Densitometry was analyzed using Image lab ${ }^{\text {TM }}$ V3.0 software (Bio-Rad Laboratories, Inc).

EdU assay. Cell proliferation was measured using an EdU assay kit (Guangzhou RiboBio Co., Ltd.) according to the manufacturer's protocol. U266 cells were cultured at a density of $1 \times 10^{5}$ cells/well in 6-well plates and treated with 1:10 concentration of anti-ALR McAb ascites, negative ascites or PBS at $37^{\circ} \mathrm{C}$ for $72 \mathrm{~h}$. A total of $50 \mu \mathrm{M}$ EdU was added to the medium and incubated for $4 \mathrm{~h}$ at $37^{\circ} \mathrm{C}$. Cells were harvested and fixed with $4 \%$ formaldehyde for $15 \mathrm{~min}$ at room temperature, centrifuged at $600 \mathrm{x}$ g for $10 \mathrm{~min}$ at room temperature, and washed with PBS. Subsequently, $2 \mathrm{mg} / \mathrm{l}$ glycine solution was used to neutralise the response, and $0.5 \%$ Triton $\mathrm{X}-100$ was added and incubated for $10 \mathrm{~min}$ at room temperature for permeabilisation. The supernatant was discarded after centrifugation (600 x g for $10 \mathrm{~min}$ at room temperature), and cells were washed again with PBS and treated with 1X Apollo reaction cocktail (100 $\mu$ l/well; Guangzhou RiboBio Co., Ltd.) in the dark for $10 \mathrm{~min}$ at room temperature. Cells were washed three times with $0.5 \%$ Triton X-100 and resuspended in $500 \mu \mathrm{l}$
PBS. Next, $1 \times 10^{4}$ cells from each sample were assessed using a FACSCanto II flow cytometer (BD Biosciences). Fluorescence data were measured and analysed using FACSCanto II software (BD Biosciences).

RNA preparation, library construction and RNA sequencing (RNA-seq). Total RNA was extracted from U266 cells $(\mathrm{n}=3$; treatmentand control groups) using TRIzol ${ }^{\circledR}$ reagent (Invitrogen; Thermo Fisher Scientific, Inc.). RNA quality was checked using a Bioanalyzer 2200 instrument (Agilent Technologies, Inc.), and cDNA libraries were constructed for each pooled RNA sample using a NEBNext Ultra Directional RNA Library Prep Kit (Illumina, Inc.) according to the manufacturer's protocol. Tagged cDNA libraries were pooled in equal ratios and used for 150-bp paired-end sequencing in a single lane of an Illumina HiSeqXTen instrument (Illumina, Inc.).

Differentially expressed genes and bioinformatics analysis. The DESeq algorithm (17) was applied to filter differentially expressed genes. The results were filtered based on fold-change (FC) and false discovery rate (FDR) using the following criteria: $\log 2 \mathrm{FC}>0.585$ or $<-0.585$, and FDR $<0.05$. Volcano plots were drawn using the $\mathrm{R}$ software package (ggplot2; version 3.2.1; https:/ggplot2.tidyverse.org/) based on the analysis of differentially expressed genes, and colour was determined by the filtering criteria. Gene Ontology (GO) analysis was performed to predict the biological functions of differentially expressed genes. GO annotations were downloaded from the National Center for Biotechnology Information (http://www.ncbi.nlm.nih.gov/), UniProt (http://www.uniprot. org/) and GO (http://www.geneontology.org/) databases. Fisher's exact tests were used to identify significant GO categories, and FDR was used to correct the P-values. FDR $<0.05$ was considered to indicate a statistically significant difference. Pathway analysis was used to identify significant pathways associated with the differentially expressed genes according to the Kyoto Encyclopedia of Genes and Genomes database (https://www.kegg.jp/). Fisher's exact tests were used to select significant pathways, and the threshold of significance was defined by the P-value and FDR $<0.05$. Protein-protein interaction (PPI) network analysis of differentially expressed genes was performed using the online Search Tool for the Retrieval of Interacting Genes/Proteins (version 11.0; https://string-db. org/) (18). The top 10 hub genes were identified using the cytoHubba plugin app of Cytoscape software (version 3.7.2) (19). Path-Act-Network (https://www.kegg.jp/kegg/pathway.html) was employed to select genes in enriched biological pathways, and Cytoscape was used for the graphical representation of pathways.

Reverse transcription-quantitative PCR (RT-qPCR). Total RNA was extracted from U266 cells using a Total RNA Extraction kit (BioTeke Corporation) according to the manufacturer's protocol. Total RNA was reverse transcribed to cDNA using a PrimeScript II Reverse Transcriptase kit (Takara Bio, Inc.) according to the manufacturer's protocol. RT-qPCR was performed using SYBR Premix (Takara Bio, Inc.). For quantitative analysis, hub genes, along with GAPDH as a positive control, were amplified using SYBR Premix on a CFX Connect Real-Time System (Bio-Rad Laboratories, Inc.). The 
Table I. Primer sequences of hub genes.

\begin{tabular}{lll} 
Gene & \multicolumn{1}{c}{ Forward sequence } & \multicolumn{1}{c}{ Reverse Sequence } \\
\hline CDK1 & 5'-GGAAACCAGGAAGCCTAGCATC-3' & 5'-GGATGATTCAGTGCCATTTTGCC-3' \\
SMC3 & 5'-ATGCGTGGAAGTCACTGCTGGA-3' & 5'-GGCAGAAAAGTAACCTCTCCAGG-3' \\
KIF11 & 5'-TACAGAAACCACTTAGTAGTGTCC-3' & 5'-GAGTTCCTGTGAGAAGCCATCAG-3' \\
SMC4 & 5'-GCCCAAGTAGCAATCAAGACTGC-3' & 5'-GCTCTGCTGTTAGGTCATCCAC-3' \\
NDC80 & 5'-CTGACACAAAGTTTGAAGAAGAGG-3' & 5'-TAAGGCTGCCACAATGTGAGGC-3' \\
NCAPG & 5'-GACGAACAGGAGGTGTCAGACT-3' & 5'-TGCTGCGGTTTTGGCTCGTCTT-3' \\
TTK & 5'-CCGAGATTTGGTTGTGCCTGGA-3' & 5'-CATCTGACACCAGAGGTTCCTTG-3' \\
CENPE & 5'-GGAGAAAGATGACCTACAGAGGC-3' & 5'-AGTTCCTCTTCAGTTTCCAGGTG-3' \\
NUF2 & 5'-TGGAGACTCAGTTGACTGCCTG-3' & 5'-ATTTGGTCCTCCAAGTTCAGGCT-3' \\
CENPU & 5'-CAGAAGGAATGAAAACCAGTGACA-3' & 5'-ATGTGGCGATGGCTGCCTTACA-3' \\
GAPDH & 5'-GGTGGTCTCCTCTGACTTCAACA-3' & 5'-GTTGCTGTAGCCAAATTCGTTGT-3'
\end{tabular}

qPCR thermocycling conditions were as follows: One cycle at $94^{\circ} \mathrm{C}$ for $30 \mathrm{sec}$, followed by 40 cycles of $5 \mathrm{sec}$ at $94^{\circ} \mathrm{C}$ for denaturation and $60^{\circ} \mathrm{C}$ for $30 \mathrm{sec}$ for annealing/extension using the two-step method. Relative gene expression levels were calculated using CFX Manager software (version 3.0; Bio-Rad Laboratories, Inc). The $2^{-\Delta \Delta \mathrm{Cq}}$ method was used to evaluate the mRNA expression (20). Primer sequences are shown in Table I.

Statistical analysis. Each experiment was performed three times separately. All quantitative data are expressed as the mean \pm standard deviation calculated using GraphPad Prism 5.0 software (GraphPad Software, Inc.). One-way ANOVA followed by Tukey's post hoc test was used to analyse differences among multiple groups. $\mathrm{P}<0.05$ was considered to indicate a statistically significant difference.

\section{Results}

Anti-ALR McAb verification and ALR expression in MM cell lines. One desirable and stable clone was screened via the limiting dilution technique. Isotypes of $\mathrm{McAb}$ were $\operatorname{IgM}$ detected using IsoQuick strips. ELISA was performed to test the ability of anti-ALR McAb to bind 15-kDa-rhALR, with a control group comprising ascites from the negative hybridoma. Absorbance $>1.5$ at OD450 $\mathrm{nm}$ and ratio of the absorbance of anti-ALR ascites to that of negative ascites $>2.1$ were considered to indicate specific binding of antigen and antibody. As shown in Fig. 1A, the absorbance values in the anti-ALR(+) ascites and negative ascites were $2.17 \pm 0.10$ vs. $1.18 \pm 0.02,2.30 \pm 0.16$ vs. $0.88 \pm 0.14,2.20 \pm 0.36$ vs. $0.49 \pm 0.01$, $1.90 \pm 0.52$ vs. $0.28 \pm 0.09,0.56 \pm 0.12$ vs. $0.19 \pm 0.04$ at dilutions ranging from 1:100 to $1: 1,000,000$, respectively. The results suggested that the antibody titer in anti-ALR McAb ascites was $10^{5}$. The absorbance values of negative ascites was $<1.5$, and as the dilution of negative ascites increased from 1:100 to 1:10 the absorbance values decreased rapidly, which suggested that there was a non-specific binding of negative ascites to rhALR protein. However, after purification, the absorbance values in purified antibody and negative control groups at OD450 nm at the dilutions of $1: 100$ and $1: 1,000$ were $0.81 \pm 0.17$ vs. $0.37+0.23$ and $0.49 \pm 0.02$ vs. $0.29 \pm 0.07$, respectively (data not shown). The
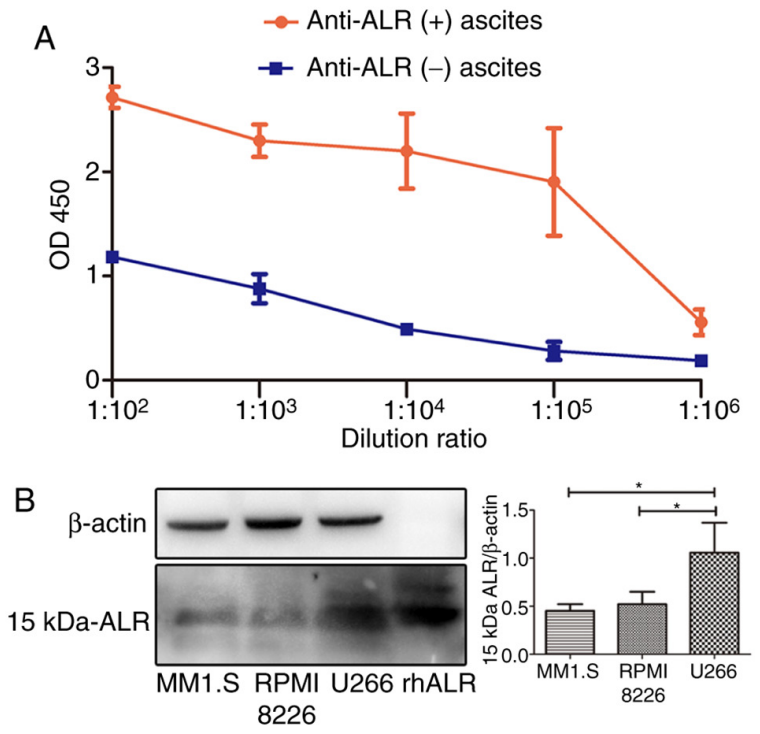

Figure 1. ELISA and western blotting verification of anti-ALR McAb. (A) ELISA showing the specific binding of anti-ALR McAb to the 15-kDa-rhALR protein. The ascites produced by the negative hybridoma cells (controls) and their binding to rhALR were markedly lower. (B) Western blot analysis showing specific binding to 15-kDa-rhALR and 15-kDa-ALR expression in different multiple myeloma cell lines. " $\mathrm{P}<0.05$. McAb, monoclonal antibody; ALR, augmenter of liver regeneration; rh, recombinant human; OD, optical density.

absorbance $<1.5$ at OD450 $\mathrm{nm}$ suggested that the titer of the antibody was markedly decreased, and therefore the purified antibody was not suitable for subsequent experiments. ELISA was used to quantify $15-\mathrm{kDa}-\mathrm{ALR}$ in the cell medium, and the concentration of 15-kDa-ALR in the medium in MM1.S, RPMI8226 and U266 cells was $152.7 \pm 21.43,200.7 \pm 31.56$ and $179.5 \pm 68.92 \mathrm{ng} / \mathrm{ml}$, respectively (data not shown), suggesting that there were no differences in the quantity of ALR in the medium. Anti-ALR McAb ascites were diluted to $1: 10,000$ as the primary antibody for western blotting, and anti-ALR McAb was found to bind specifically to 15-kDa-rhALR (Fig. 1B). The expression levels of 15-kDa-ALR in different MM cell lines were investigated, and U266 cells displayed the highest expression levels among the three MM cell lines (Fig. 1B); hence, this cell line was selected for further experiments. 

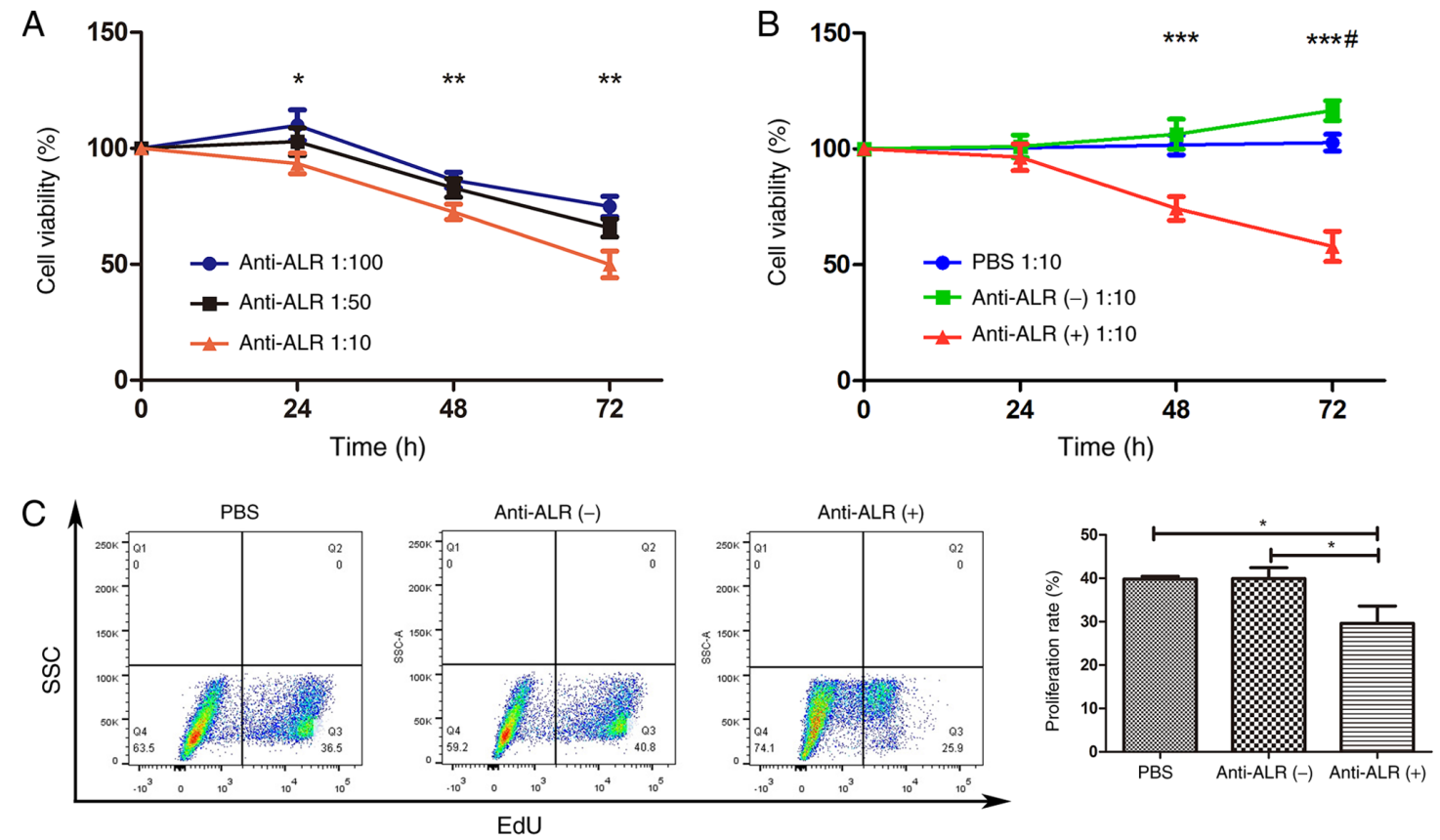

Figure 2. Cell survival rate and proliferation in the anti-ALR McAb, negative ascites and PBS groups. (A) U266 cells treated with anti-ALR McAb at different concentrations (1:10, 1:50 and 1:100 ratios of ascites to medium) for different durations. ${ }^{*} \mathrm{P}<0.05$ and ${ }^{* *} \mathrm{P}<0.01$ 1:10 dilution vs. 1:50 and 1:100 dilutions. (B) U266 cells treated with anti-ALR McAb, negative ascites or PBS at a concentration of 1:10 for different durations. ${ }^{* * *} \mathrm{P}<0.001$ anti-ALR McAb group vs. negative ascites and PBS groups. ${ }^{~} \mathrm{P}<0.05$ negative ascites group vs. PBS group. (C) Proliferation, as measured by EdU assay, of U266 cells treated with anti-ALR McAb vs. negative ascites and PBS at a concentration of 1:10 for $72 \mathrm{~h} .{ }^{*} \mathrm{P}<0.05$. McAb, monoclonal antibody; ALR, augmenter of liver regeneration; SSC, side scatter.

Effect of blocking 15-kDa-ALR on cell survival and proliferation. To construct a cell model, U266 cells were treated with different $\mathrm{McAb}$ concentrations (1:100, 1:50 and 1:10 ratio of ascites to medium) for different durations (24, 48 and $72 \mathrm{~h}$ ). The CCK- 8 assay results revealed that, when treated at 1:100 and 1:50 dilutions for $24 \mathrm{~h}$, cell viability increased slightly, and then decreased after 48 and $72 \mathrm{~h}$. The higher the concentration, the lower the cell viability when cells were treated for 48 and $72 \mathrm{~h}$. At a 1:10 concentration, cell viability decreased in a time-dependent manner, and cell viability was significantly lower than that at the other two concentrations at $24 \mathrm{~h}(96.43 \pm 5.78,101.11 \pm 4.79$ and $100.44 \pm 2.60 \%$ at $1: 10,1: 50$ and 1:100, respectively; $\mathrm{P}<0.05), 48 \mathrm{~h}(72.62 \pm 3.35,82.95 \pm 3.98$ and $86.31 \pm 3.39 \%$ at $1: 10,1: 50$ and $1: 100$, respectively; $\mathrm{P}<0.01$ ) and $72 \mathrm{~h}(49.97 \pm 3.31,65.72 \pm 2.26$ and $74.93 \pm 2.55 \%$ at $1: 10$, 1:50 and 1:100, respectively; $\mathrm{P}<0.01$ ) (Fig. $2 \mathrm{~A}$ ). Therefore, a concentration of 1:10 was selected for subsequent experiments.

Next, cell viability was compared among the anti-ALR treatment, negative ascites and PBS groups. The results revealed that PBS had no influence on cell viability at a concentration of 1:10, regardless of treatment duration. Cell viability increased slightly in the negative ascites group at a concentration of 1:10 after $72 \mathrm{~h}$ compared with $48 \mathrm{~h}$, and there was a significant difference between the negative ascites and PBS groups $(\mathrm{P}<0.05 ;$ Fig. $2 \mathrm{~B})$. The effect of the anti-ALR $\mathrm{McAb}$ on survival rate at 48 and $72 \mathrm{~h}$ was significantly lower than that in the other two groups $(\mathrm{P}<0.001$; Fig. $2 \mathrm{~B})$. Thus, an anti-ALR McAb concentration of 1:10 for $72 \mathrm{~h}$ was selected for subsequent experiments, with the same concentration of negative ascites as the control and PBS blank groups.

Cell proliferation was measured using EdU assay, and treatment with anti-ALR McAb, negative ascites and PBS yielded U266 cell proliferation rates of $23.77 \pm 1.39,37.17 \pm 1.93$ and $36.33 \pm 0.55$, respectively $(\mathrm{P}<0.01$; Fig. $2 \mathrm{C})$.

Effect of blocking 15-kDa-ALR on apoptosis. Since the anti-apoptotic effect of exogenous ALR in the liver has been demonstrated in various injury models $(21,22)$, apoptosis in U266 cells was investigated via flow cytometry and western blotting (Fig. 3). When treated with McAb for $72 \mathrm{~h}$, the proportion of apoptotic cells (both late and early apoptotic cells) detected by flow cytometry did not differ between the three groups $(7.70 \pm 0.29,10.91 \pm 3.79$ and $7.11 \pm 0.74 \%$ for the $\mathrm{McAb}$, negative ascites and PBS groups, respectively; Fig. 3A). Additionally, the expression levels of the pro-apoptotic protein Bax and the anti-apoptotic protein Bcl-2 were measured, and there was no difference in the ratio of the two proteins between the three groups $(\mathrm{P}>0.05$; Fig. 3B). Similarly, there were no differences in caspase-3 expression and in the ratio of cleaved caspase-3/caspase-3 (P>0.05; Fig. 3B). However, following cell injury induced by $0.004 \mathrm{mg} / \mathrm{ml}$ epirubicin treatment for $24 \mathrm{~h}$, the proportion of apoptotic cells was significantly increased after blocking extracellular ALR with $\mathrm{McAb}(\mathrm{P}<0.05$; Fig. 3C).

Differentially expressed genes. To clarify how extracellular ALR affected U266 MM cells, RNA-Seq was performed to identify differentially expressed RNAs between the anti-ALR McAb and negative ascites groups. A total of 20,030 genes were subjected to differential gene analysis after filtering low-abundance genes, and the results revealed 289 and 138 significantly upregulated and downregulated genes, respectively. Hierarchical cluster analysis confirmed the quality of the microarray data and the differences between the treatment and control groups (Fig. 4A). The distribution of RNAs is shown in a volcano plot (Fig. 4B). 

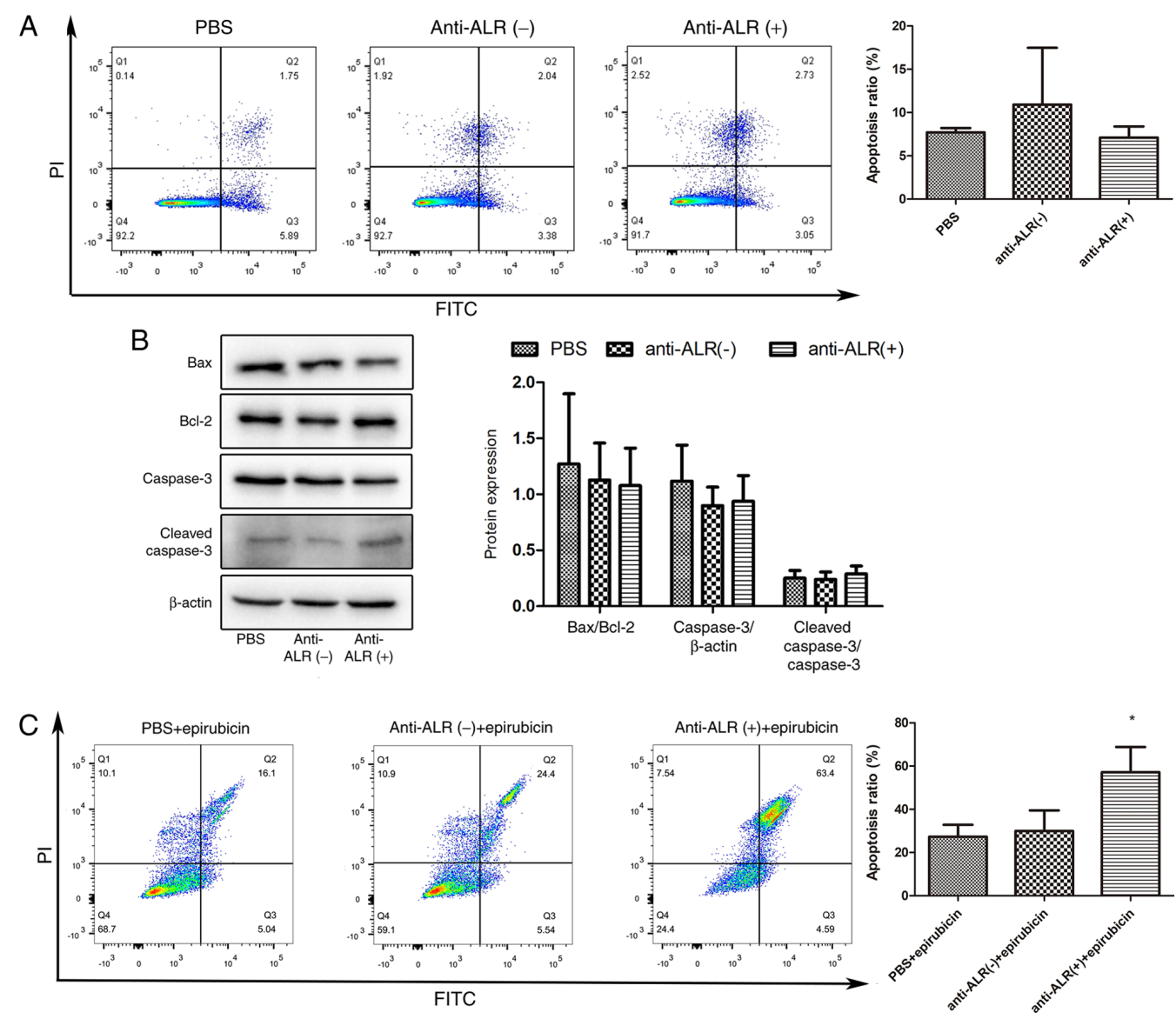

Figure 3. Apoptosis of U266 cells treated with anti-ALR McAb, negative ascites or PBS. (A) Flow cytometry analysis of the apoptosis of U266 cells treated with anti-ALR McAb, negative ascites or PBS at a concentration of 1:10 for $72 \mathrm{~h}$, followed by Annexin V-FITC/PI staining. (B) Analysis of apoptosis-associated protein expression by western blotting. U266 cells were harvested to examine the expression levels of Bax, Bcl-2, caspase-3 and cleaved caspase-3 after treatment with anti-ALR McAb, negative ascites or PBS at a concentration of 1:10 for $72 \mathrm{~h}$. (C) U266 cells treated with anti-ALR McAb, negative ascites or PBS at a concentration of 1:10 for $48 \mathrm{~h}$ were co-treated with epirubicin at $0.004 \mathrm{mg} / \mathrm{ml}$ for $24 \mathrm{~h}$, and apoptosis was examined by flow cytometry after Annexin V-FITC/PI staining. "P<0.05 anti-ALR McAb group vs. negative ascites and PBS groups. McAb, monoclonal antibody; ALR, augmenter of liver regeneration.
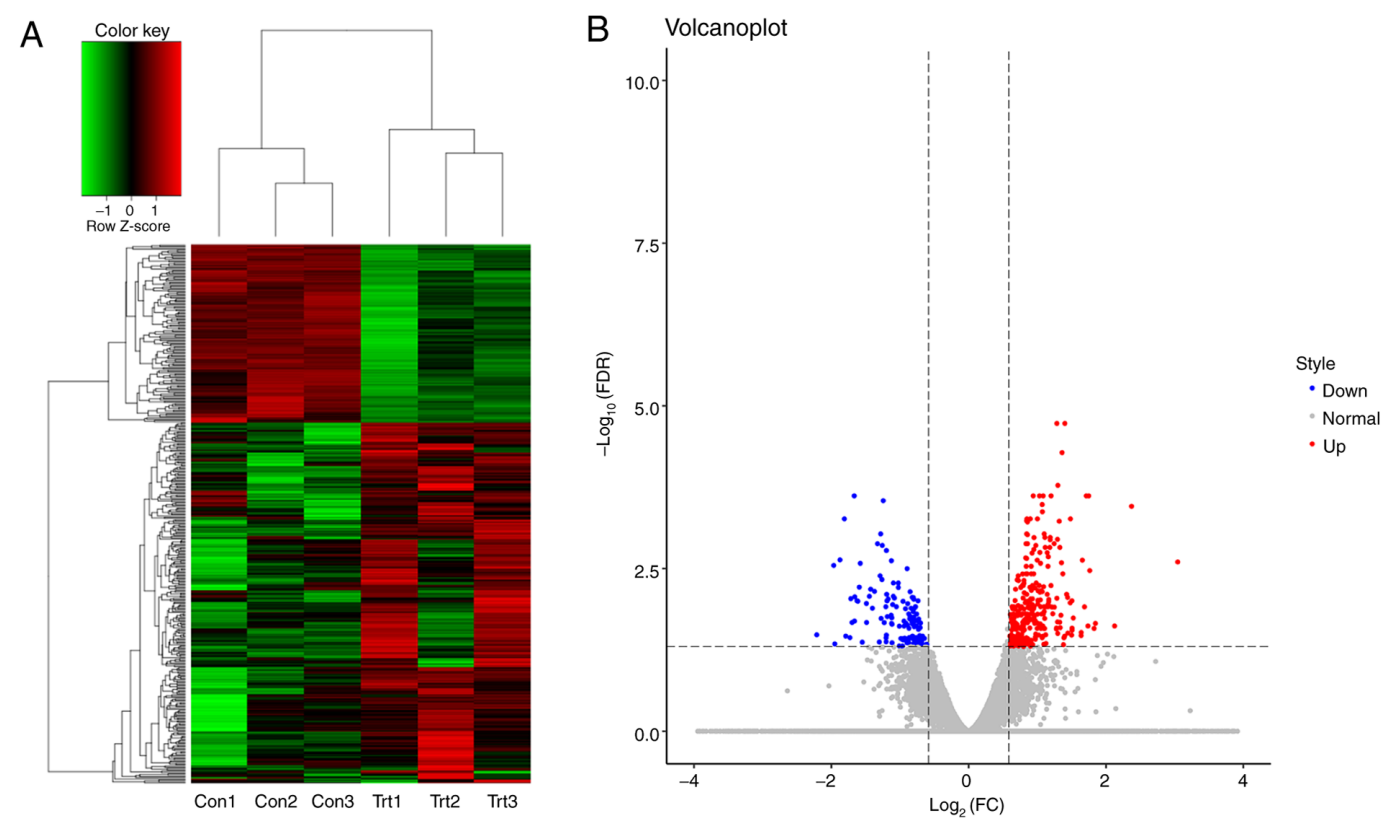

Figure 4. Differentially expressed genes between the anti-ALR McAb and negative control groups, as assessed by RNA-sequencing. (A) Heat map analysis of differentially expressed genes in U266 cells treated with anti-ALR McAb (trt) or negative ascites (con). Red indicates genes with higher expression, green indicates genes with lower expression and black indicates genes not differing in terms of their expression levels between the two groups. (B) Volcano plots showing the number, significance and reliability of differentially expressed genes between the two groups. Red dots indicate upregulation, while blue dots indicate downregulation. McAb, monoclonal antibody; ALR, augmenter of liver regeneration; FDR, false discovery rate; FC, fold-change; trt, treatment group; con, control group. 
A
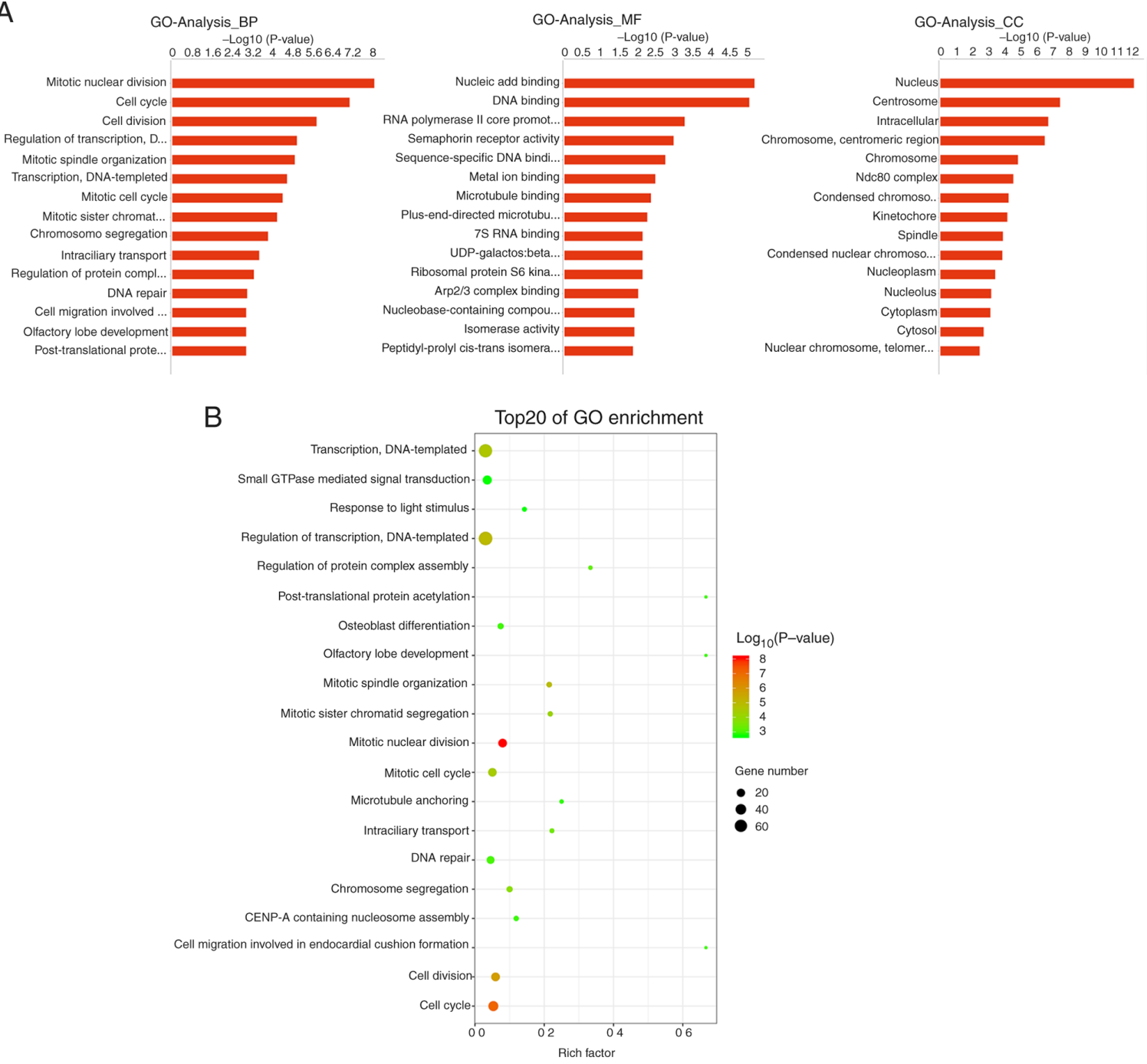

Figure 5. GO analysis of differentially expressed genes. (A) GO divided into BP, MF and CC categories. The top 15 -log10 values are shown. (B) GO enrichment analysis showing the top 20 GO-term categories for differentially expressed genes. The $\mathrm{x}$-axis represents the rich factor, which refers to the ratio of the number of differentially expressed genes enriched in the GO category versus the total number of genes annotated in the GO category. The larger the rich factor, the greater the degree of enrichment. The colour of the dots indicates the P-value; the smaller the P-value, the redder the colour, while larger P-values are represented by greener colour. The size of the dots indicates the number of differentially expressed genes contained in each GO category; the larger the number of differentially expressed genes, the larger the dots. GO, Gene Ontology; BP, biological process; MF, molecular function; CC, cellular component.

GO, pathway enrichment, Path-Act-Network and PPI network analyses, and hub gene validation. GO analysis revealed that differential genes in the biological process category were primarily associated with 'mitotic nuclear division', 'cell cycle' and 'cell division', while those in the molecular function category were associated with 'nucleic acid binding', 'DNA binding' and 'RNA polymerase II core promoter proximal region sequence-specific DNA binding'; the cellular component category was primarily enriched in terms associated with 'nucleus', 'centrosome' and 'intracellular' functions (Fig. 5A). GO enrichment analysis revealed that these differential genes were mainly associated with 'cell cycle', 'cell division', 'mitotic nuclear division' and 'mitotic cell cycle' (Fig. 5B), all of which are associated with cell proliferation.

Pathway analysis based on gene annotation databases can identify pathways in which differentially expressed genes are significantly enriched, and pathways can directly reflect the effects of genes on phenotypes (23). In the present study, 12 signaling pathways were significantly different between groups (Fig. 6A), and the top three pathways were 'pyrimidine metabolism', 'Fanconi anaemia pathway' and 'oocyte meiosis' (Fig. 6B).

The PPI network based on the identified differentially expressed genes is shown in Fig. 7A. The top 10 genes were CDK1, SMC3, KIF11, SMC4, NDC80, NCAPG, TTK, CENPE, NUF2 and CENPU, all of which are potential hub genes according to the scores generated by the cytoHubba plugin app (Fig. 7B). Path-Act-Network analysis was used to probe signal transmission and regulation processes among the various signaling pathways, and MAPK, cell cycle and JAK-STAT were identified as the key signaling pathways (Fig. 7C).

Hub gene and pathway validation. The top 10 hub genes were validated via RT-qPCR, and the results are shown in Fig. 8. The relative mRNA expression levels of CDK1 were downregulated, while those of the other nine hub genes were upregulated in the anti-ALR McAb group compared with in 
A

A

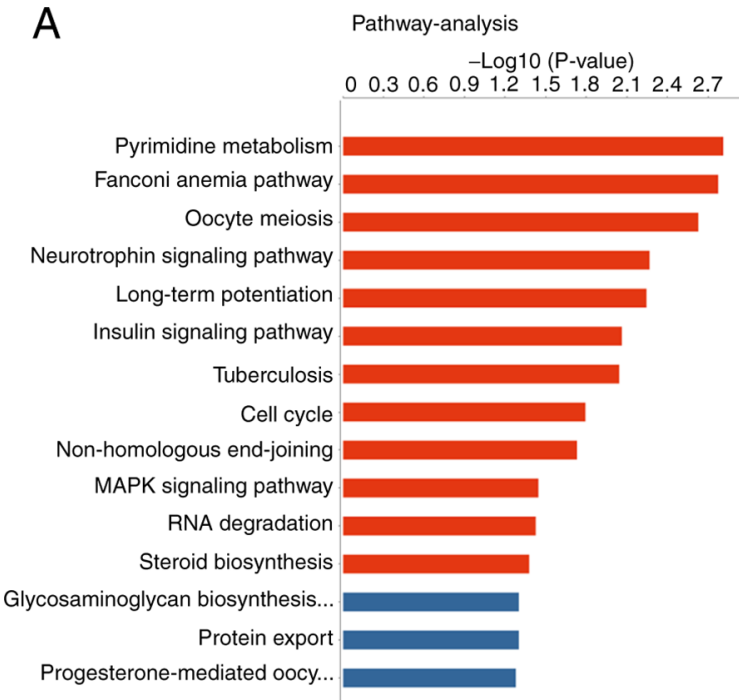

$\mathrm{B}$

B

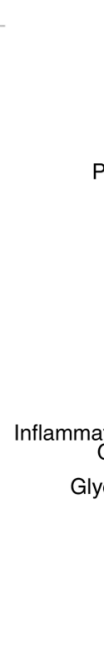

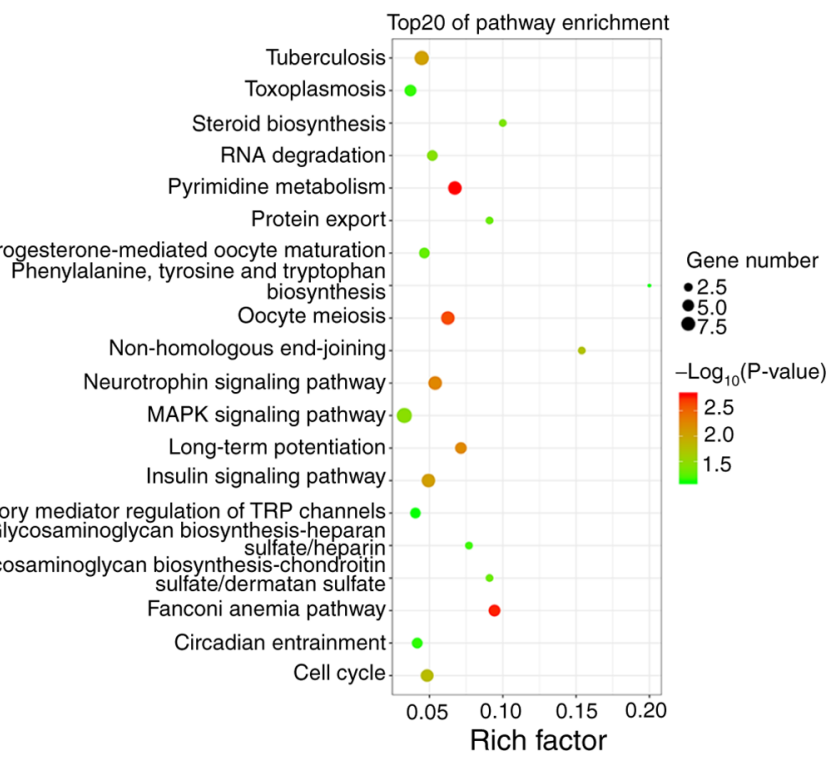

Top20 of pathway enrichment

Figure 6. Pathway analysis of differentially expressed genes. (A) Pathway terms associated with differentially expressed genes. Red represents significant terms and blue represents non-significant terms. (B) Top 20 pathways enriched with differentially expressed genes. The colour of the dots indicates the P-value; the smaller the P-value, the redder the colour, while larger P-values are represented by greener colour. The size of the dots indicates the number of differential genes contained in each category; the larger the number of differential genes, the larger the dots.

the negative ascites and PBS groups. The changes in hub genes were consistent with the microarray results. However, the changes in TTK and CENPU were not statistically significant.

Signaling pathways were verified via western blotting. The MAPK pathway includes the p44/42, p38 and JNK cascades (24). The protein expression levels of $\mathrm{p} 44 / 42$ were downregulated in the anti-ALR McAb treatment group compared with in the negative ascites and PBS groups, while p38 and phospho-p38 exhibited no significant difference in expression. JNK expression was significantly downregulated, while phospho-JNK expression was significantly upregulated in the anti-ALR McAb group compared with in the negative ascites and PBS groups (Fig. 9A). Additionally, STAT3 expression was significantly downregulated in the treatment group compared with in the negative ascites and PBS groups, (Fig. 9B), as well as that of CDK1 and cyclin D1 (Fig. 9C). Cell cycle analysis revealed cell cycle arrest at the $S$ phase in the anti-ALR McAb group, but not in the PBS or negative control groups (Fig. 9D).

\section{Discussion}

ALR mRNA expression has been previously detected in several tissues, being relatively high in liver, kidney, testis and brain $(5,25)$. Additionally, ALR has been found in the serum in both rat bacterial sepsis and mouse hemorrhagic shock models (21). ALR expression is upregulated in a number of solid tumours, such as hepatocellular carcinoma $(22,26)$, colon cancer (27) and T-cell leukaemia (28), and overexpression of ALR has a protective effect on these tumour cells. Furthermore, a protective effect of ALR was observed in neuroblastoma (29) and glioma (30). Our previous study revealed that ALR expression was higher in U266 MM cells than in human peripheral blood mononuclear cells (15). Our research group has detected 15-kDa-ALR in patients with MM (unpublished data). In small samples of bone marrow, the expression levels of 15-kDa-ALR in myeloma cells were higher than those in healthy volunteers (unpublished data). However, the sample size was too small for statistical analysis, and it was difficult to obtain bone marrow samples just for this experiment, so the data was unpublished. In the present study, U266 cells exhibited the highest expression levels of 15-kDa-ALR among the three cell lines evaluated and the best response to the 15-kDa-ALR McAb.

A McAb was used to block 15-kDa-ALR, which is secreted from cells, and can therefore avoid the influence of 23-kDa-ALR (9). In present study, an IgM purification column was used to perform IgM purification. However, after purification, the absorbance value of the purified antibody was $<1.5$ at OD450 $\mathrm{nm}$. The results suggested that the purified antibody was not suitable for subsequent experiments. The ascites containing McAb were selected for subsequent experiments. Ascites produced by a negative hybridoma that cannot produce anti-15-kDa-ALR McAb were used as a negative control. The impurities in the ascites made it impossible to accurately estimate the concentration of antibodies. Thus, the ascites were mixed for the experiment to ensure the same quantity of antibody in the same volume of ascites. The present CCK- 8 results revealed that the survival rate of U266 MM cells was negatively associated with the concentration of $\mathrm{McAb}$, which confirmed that low levels of 15-kDa-ALR confer a weaker protective effect. This information is consistent with the results from a previous in vivo model of acute liver injury (31) and a previous in vitro model of acute injury (32). The cell viability was increased in the negative ascites group compared with in the anti-ALR McAb group at a concentration of 1:10 after $72 \mathrm{~h}$, and the difference between the negative ascites and PBS groups was statistically significant. It was speculated that the reason for this may be that negative ascites are rich in albumin and other factors, but not in anti-ALR $\mathrm{McAb}$, which may provide nutrition to cells without being 
A
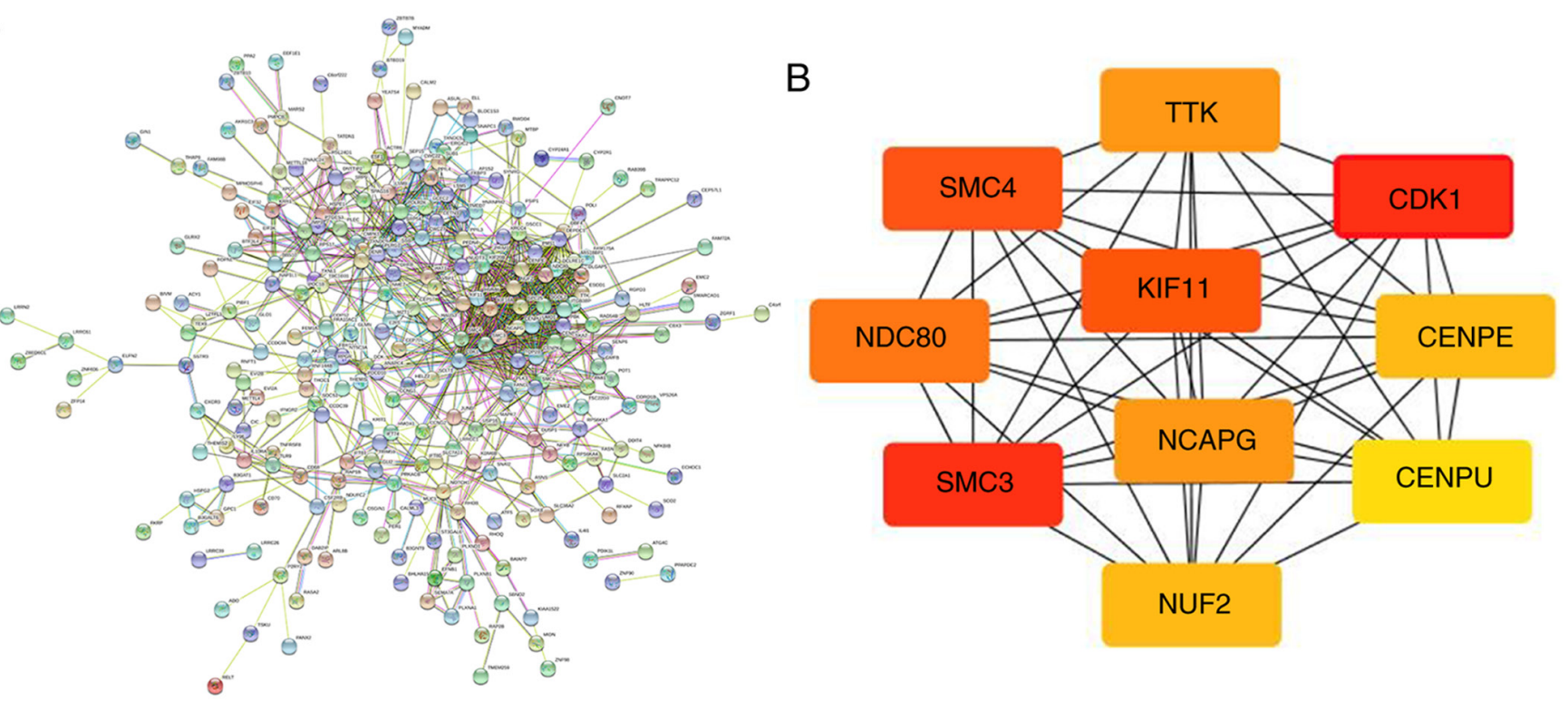

C

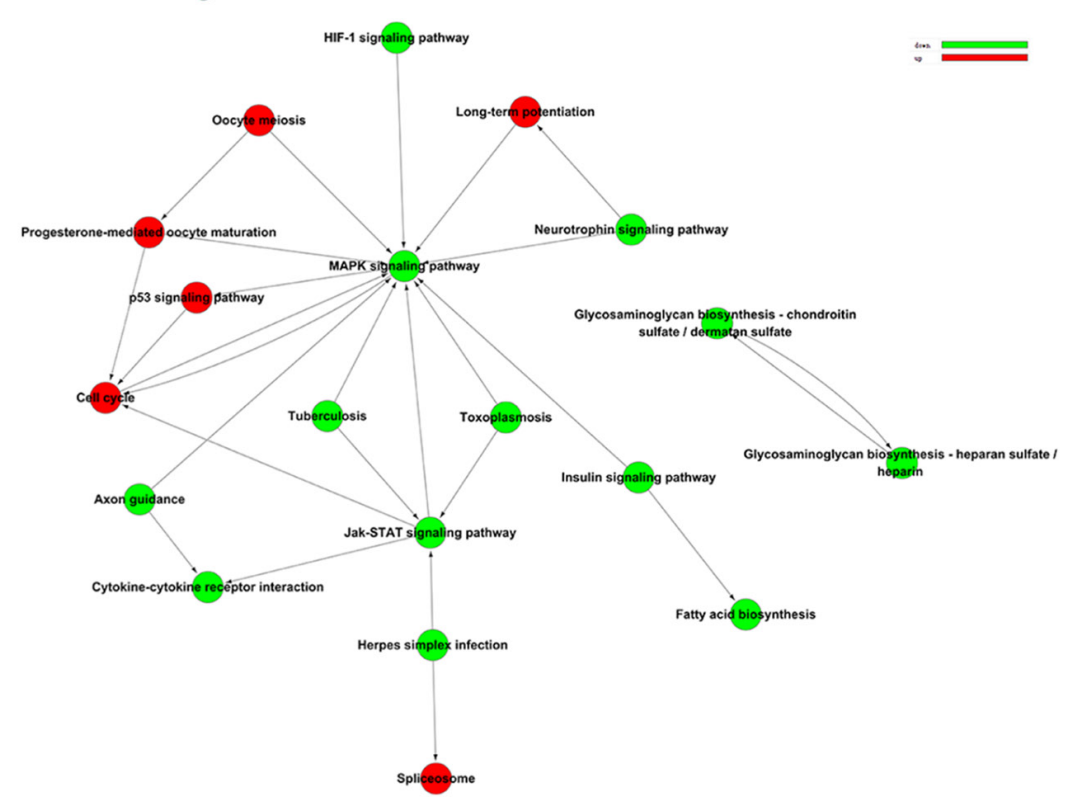

Figure 7. PPI network and Path-Act-Network analyses. (A) The online Search Tool for the Retrieval of Interacting Genes/Proteins (version 11.0) was used to construct the PPI network. Each node represents all proteins produced by a single protein-coding gene locus. Coloured nodes represent differentially expressed genes and the first shell of interactors. Edges represent protein-protein associations. (B) Top 10 hub genes identified using the cytoHubba plugin app of Cytoscape using the degree calculation method. The redder the node color, the higher the ranking. (C) Path-Act-Network analysis showing the upstream and downstream associations of significant signaling pathways. Red represents pathways that are significant only for upregulated genes, while green represents pathways that are significant only for downregulated genes. PPI, protein-protein interaction.

inhibited by anti-ALR McAb, which increased cell viability in the negative ascites group. Previous research demonstrated that exogenous ALR can induce proliferation in hepatocytes (33), and decrease apoptosis in liver cells $(32,34)$, kidney cells $(35,36)$ and lymphocytes $(37)$. In order to verify whether 15-kDa-ALR had the same effect in U266 MM cells, EdU assays were used to assess cell proliferation. Treatment with the 15-kDa-ALR McAb decreased the cell proliferation rate compared with that of the control group, which was consistent with the effect of exogenous ALR on hepatocytes (38). The current results of CCK- 8 and EdU assays demonstrated that 15-kDa-ALR secreted by U266 cells induced cell proliferation and that when autocrine ALR was blocked, cell proliferation decreased.
The anti-apoptotic effect of exogenous ALR has been demonstrated in different liver and kidney injury models $(34,35)$. Exogenous ALR decreases caspase-3 activity, which may be due to decreased Bax expression (39). Furthermore, a previous study revealed that exogenous ALR decreases cell damage after partial hepatectomy by inducing anti-apoptotic Bcl-2 expression, suggesting that exogenous ALR enhances liver regeneration through apoptosis attenuation (34). Based on these findings, the present study hypothesized that apoptosis would increase if extracellular 15-kDa-ALR was blocked using a McAb. However, when U266 cells were treated with the McAb, apoptosis did not increase as expected. The flow cytometry results revealed that there was no difference in apoptosis, and western blotting indicated no differences in 


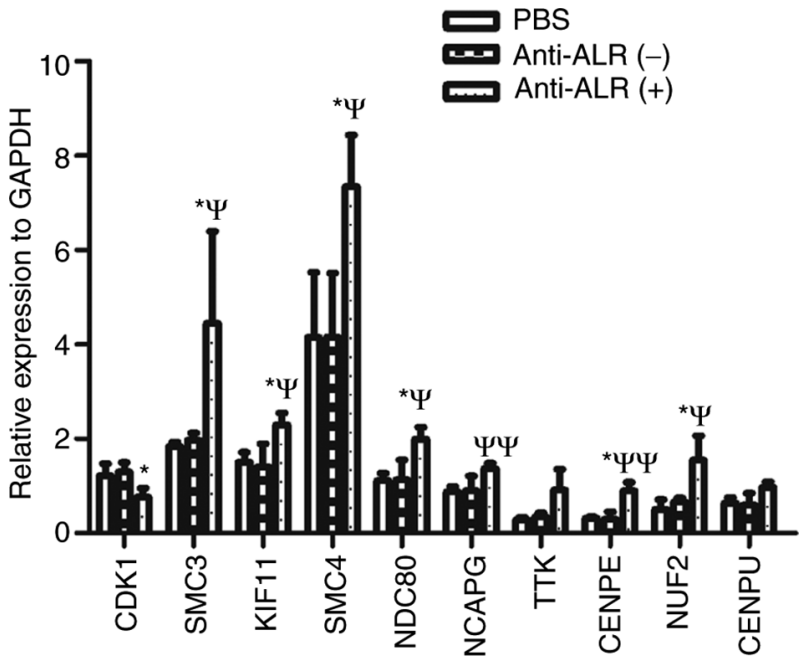

Figure 8. Validation of hub genes identified using the cytoHubba plugin app by RT-qPCR. Total RNA from U266 cells was extracted after treatment with anti-ALR McAb, negative ascites or PBS at a concentration of 1:10 for $72 \mathrm{~h}$. Relative mRNA expression levels of hub genes were measured by RT-qPCR, with GAPDH as a reference gene. ${ }^{*} \mathrm{P}<0.05$ anti-ALR McAb vs. negative ascites groups. ${ }^{\Psi} \mathrm{P}<0.05$ and ${ }^{\Psi \Psi} \mathrm{P}<0.01$ anti-ALR McAb vs. PBS groups. RT-qPCR, reverse transcription-quantitative PCR; McAb, monoclonal antibody; ALR, augmenter of liver regeneration.

the expression levels of Bax, Bcl-2 or caspase-3. Thus, the $\mathrm{Bax} / \mathrm{Bcl}-2$ ratio did not differ. The flow cytometry and western blotting results on apoptosis were inconsistent with previous research (32). This may be due to the fact that, in the present study, there were no injury factors such as $\mathrm{TNF} \alpha$, lipopolysaccharide or ischemia reperfusion, which may cause apoptosis; hence, blocking extracellular 15-kDa-ALR with antibodies alone may not be sufficient to stimulate apoptosis. However, a previous study revealed that silencing ALR triggered apoptosis in U266 cells without injury factors (15). Small hairpin RNA was used for silencing ALR expression in a previous study (15), which influenced 23- and 15-kDa-ALR at the same time. The 23-kDa-ALR is located in mitochondria and is involved in the process of oxidative phosphorylation, which is essential for life. When 23-kDa-ALR is silenced, apoptosis is triggered (38). In the present study, McAb blocked extracellular 15-kDa-ALR without influencing 23-kDa-ALR, which may be the reason for the inconsistent results with previous studies. Therefore, epirubicin, a traditional chemotherapy drug used to induce apoptosis (40), was employed in the present study. When the injury factor was present, apoptosis was increased as expected. These results confirmed that extracellular 15-kDa-ALR promoted proliferation in the absence of external injury factors, and the anti-apoptotic effect also occurred in the presence of injury factors.

A previous study demonstrated that the mechanisms of exogenous ALR affect the liver and that the MAPK signaling pathway is important in cell proliferation (14). In the present study, 15-kDa-ALR in the medium of U266 cells was detected by ELISA, which suggested that U266 cells may secrete $15-\mathrm{kDa}-\mathrm{ALR}$. In the early research of our group, MTS assay was used to evaluate the influence of exogenous ALR on the proliferation of U266 cells, and the results suggested that after treating with exogenous ALR, the proliferation of U266 cells was significantly increased (unpublished data); however, the signal transduction mechanism in U266 cells was unclear. The use of an antibody to block extracellular 15-kDa-ALR in the present study was part of a research project on the signal transduction mechanism of $15-\mathrm{kDa}-\mathrm{ALR}$ in U266 cells. GO and pathway analysis of RNA-seq revealed that $15-\mathrm{kDa}-\mathrm{ALR}$ affected U266 cells via the MAPK signaling pathway, similar to the findings in hepatocytes (41). The MAPK signaling pathway involves ERKs, JNKs and p38-MAPKs. In the present study, western blotting indicated that the expression levels of p44/42 were downregulated in the treatment group. p44/42 can be activated by a variety of factors, such as inflammation (42) and heart failure (43), and this may be coincident with the activation of other pathways that promote contradictory biological responses (44). Combining the Path-Act-Network analysis and western blotting results demonstrated that p44/42 in the MAPK signaling pathway was downregulated by blocking extracellular 15-kDa-ALR and decreasing the proliferation of U266 cells. The expression levels of JNK and phospho-JNK were also altered in the present study, demonstrating that the JNK signaling pathway may be involved in the mechanism of blocking ALR in U266 cells. A recent study revealed that xanthohumol exhibits anti-myeloma activity via an ERK- and JNK-dependent mechanism in RPMI8226 cells (45). Similar to the aforementioned study, the present results indicated that the ERK1/2 and JNK signaling pathways may serve a role in anti-myeloma effects, but changes in protein expression depended on different stimuli. The expression levels of p38 and phospho-p38 were not significantly altered among the three groups; hence, the p38 signaling pathway may not be involved in the mechanisms of blocking 15-kDa-ALR. In MM cells, when the activity of the STAT3 signaling pathway was inhibited, cyclin D1 expression was downregulated, which inhibited the proliferation of myeloma cells and induced apoptosis (46). In the present study, STAT3 and cyclin D1 expression was attenuated by blocking extracellular $15-\mathrm{kDa}-\mathrm{ALR}$, consistent with the results of a previous study (47), suggesting that the STAT3 signaling pathway may serve an important role in MM cells. However, STAT3 is attenuated by exogenous ALR (47), which contradicts the current findings, possibly due to the lack of injury factors in the present study.

According to the PPI network, the top 10 hub genes were associated with the cell cycle. In the current study, CDK1 expression was downregulated at both the mRNA and protein levels, and cell cycle analysis indicated that blocking $15-\mathrm{kDa}-A L R$ caused cell cycle arrest in the $\mathrm{S}$ phase. A previous study on hematopoietic stem cells demonstrated that binding of ALR to JAB1 blocks JAB1 interaction with p27kip1, which promotes cell cycle arrest (48). Another study on leukemia suggested that changes in the MAPK signaling pathway may lead to S-phase cell cycle arrest (49). The mechanism of the cell cycle arrest induced by blocking 15-kDa-ALR may involve the combined effects of blocking the binding of ALR to JAB1 and the regulation of the MAPK signaling pathway induced by the anti-ALR McAb. The other hub genes identified in the present study included members of the centromere protein family (CENPE and CENPU), the nuclear division cycle 80 family (NDC80 and NUF2) and the SMC family 
A

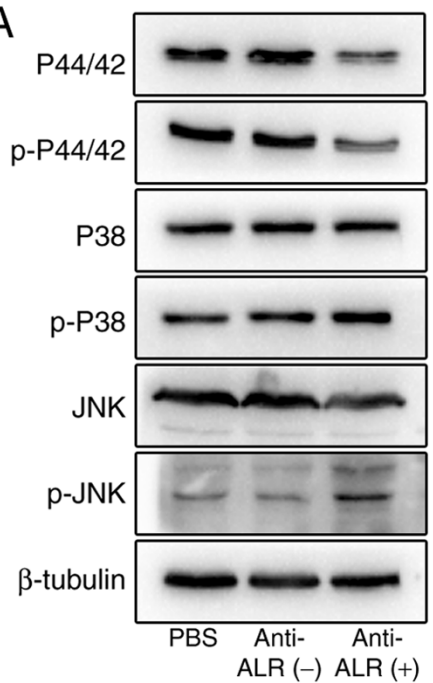

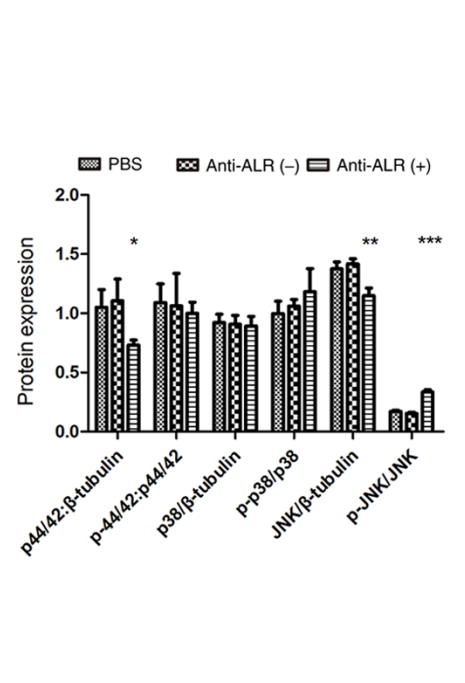
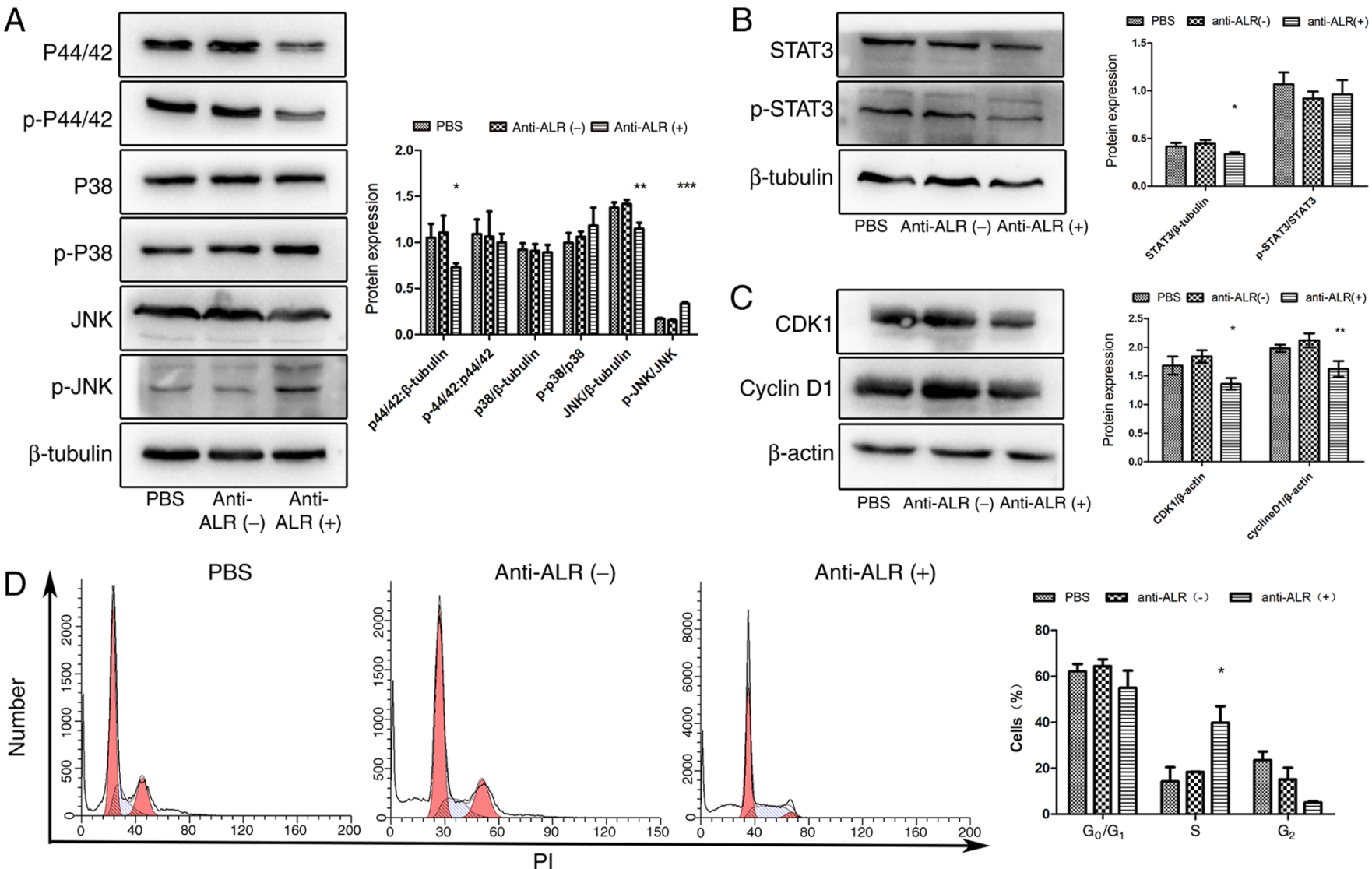

Figure 9. Verification of changes in signaling pathways after treatment with anti-ALR McAb, negative ascites or PBS at a concentration of 1:10 for $72 \mathrm{~h}$ (A) Expression levels of important proteins in the MAPK signaling pathway, including p44/42, p38 and JNK, as assessed by western blotting. (B) STAT3 protein expression in the three groups. (C) Expression levels of cell cycle-associated proteins, including CDK1 and cyclin D1, in the three groups. (D) Flow cytometry analysis of the cell cycle after PI staining. The $\mathrm{x}$-axis represents the DNA content, while the $y$-axis represents the number of cells. ${ }^{*} \mathrm{P}<0.05,{ }^{* * *} \mathrm{P}<0.01$,

${ }^{* * * *} \mathrm{P}<0.001$ anti-ALR McAb vs. negative ascites and PBS groups. McAb, monoclonal antibody; ALR, augmenter of liver regeneration; $p$, phospho.

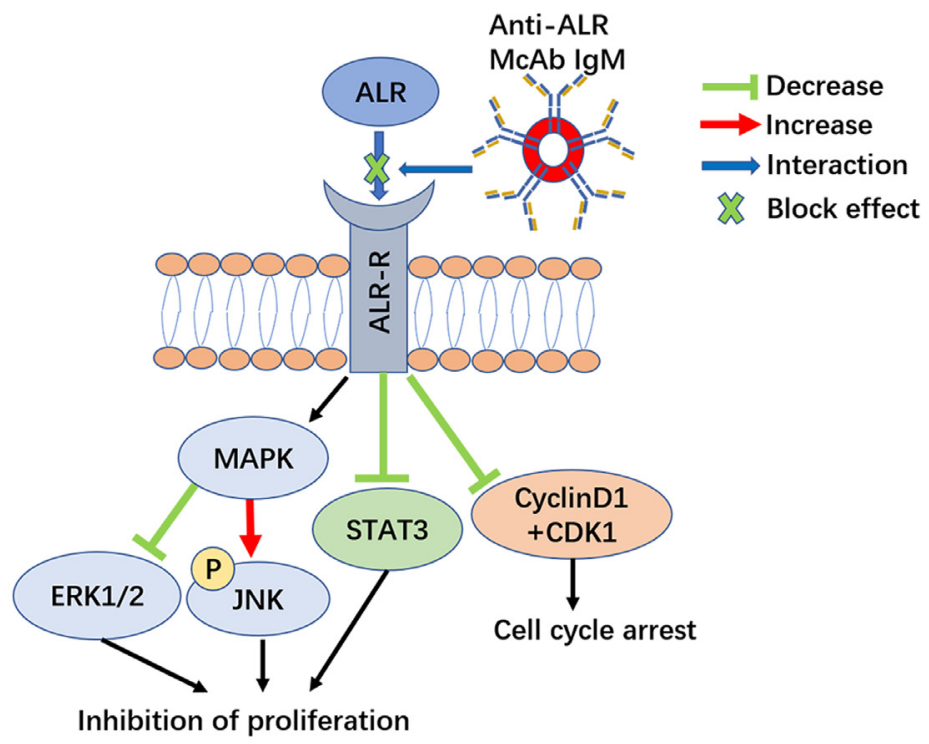

Figure 10. Schematic summary demonstrating the molecular mechanism of anti-ALR McAb inhibiting the proliferation of U266 cells. McAb, monoclonal antibody; ALR, augmenter of liver regeneration.

(SMC3, SMC4 and NCAPG), all of which are associated with chromosome changes in the cell cycle. The expression levels of these genes were upregulated following anti-ALR treatment, which may be due to the fact that the cell cycle was arrested in $\mathrm{S}$ phase, inducing the upregulation of these genes when blocking 15-kDa-ALR.

In conclusion, the current results provided evidence that blocking extracellular 15-kDa-ALR inhibited the proliferation 
of U266 MM cells through cell cycle arrest without increasing apoptosis in the absence of injury factors. The ERK1/2 and JNK branches of the MAPK signaling pathway, STAT3 signaling pathway and the cell cycle appeared to be involved in the possible mechanism (Fig. 10). Thus, 15-kDa-ALR may be a novel target for myeloma treatment.

\section{Acknowledgements}

The authors would like to thank Mrs. Wanyan Deng and Mr. Fang Jia (The Second Affiliated Hospital of Chongqing Medical University, Chongqing, China) for their assistance in analysing the data and formatting the manuscript.

\section{Funding}

The present study was supported by a grant from the National Natural Science Foundation of China (grant no. 81871608).

\section{Availability of data and materials}

The datasets used and/or analyzed during the current study are available from the corresponding author on reasonable request.

\section{Authors' contributions}

WH contributed to the conceptualization and investigation of the study, data curation and writing of the original draft. HS contributed to the conceptualization of the study, funding acquisition and review and editing of the manuscript. $\mathrm{TH}$ contributed to the analysis of experimental data. DZ, XL and HG performed the experiments. QL contributed to the conceptualization and supervision of the study. All authors read and approved the final manuscript.

\section{Ethics approval and consent to participate}

All experimental procedures involving animals were approved by the Animal Ethics and Use Committee of the Second Affiliated Hospital of Chongqing Medical University (Chongqing, China).

\section{Patient consent for publication}

Not applicable.

\section{Competing interests}

The authors declare that they have no competing interests.

\section{References}

1. Kazandjian D: Multiple myeloma epidemiology and survival: A unique malignancy. Semin Oncol 43: 676-681, 2016.

2. Kristinsson SY, Anderson WF and Landgren O: Improved long-term survival in multiple myeloma up to the age of 80 years. Leukemia 28: 1346-1348, 2014.

3. Landgren $\mathrm{O}$ and Iskander K: Modern multiple myeloma therapy: Deep, sustained treatment response and good clinical outcomes. J Intern Med 281: 365-382, 2017.

4. Sonneveld P and Broijl A: Treatment of relapsed and refractory multiple myeloma. Haematologica 101: 396-406, 2016.
5. Hagiya M, Francavilla A, Polimeno L, Ihara I, Sakai H, Seki T, Shimonishi M, Porter KA and Starzl TE: Cloning and sequence analysis of the rat augmenter of liver regeneration (ALR) gene: Expression of biologically active recombinant ALR and demonstration of tissue distribution. Proc Natl Acad Sci USA 91: 8142-8146, 1994.

6. Lu J, Xu WX, Zhan YQ, Cui XL, Cai WM, He FC and Yang XM: Identification and characterization of a novel isoform of hepatopoietin. World J Gastroenterol 8: 353-356, 2002.

7. Hofhaus G, Lee JE, Tews I, Rosenberg B and Lisowsky T: The $\mathrm{N}$-terminal cysteine pair of yeast sulfhydryl oxidase Ervlp is essential for in vivo activity and interacts with the primary redox centre. Eur J Biochem 270: 1528-1535, 2003.

8. Cheng J,Zhong YW, Liu Y, Dong J, Yang JZ and Chen JM: Cloning and sequence analysis of human genomic DNA of augmenter of liver regeneration. World J Gastroenterol 6: 275-277, 2000.

9. Gandhi CR, Kuddus R, Subbotin VM, Prelich J, Murase N, Rao AS, Nalesnik MA, Watkins SC, DeLeo A, Trucco M, et al: A fresh look at augmenter of liver regeneration in rats. Hepatology 29: 1435-1445, 1999.

10. Fass D: The Erv family of sulfhydryl oxidases. Biochim Biophys Acta 1783: 557-566, 2008

11. Jung YS, Kim SJ, Kwon DY, Jun DS and Kim YC: Significance of alterations in the metabolomics of sulfur-containing amino acids during liver regeneration. Biochimie 95: 1605-1610, 2013.

12. Ferecatu I, Gonçalves S, Golinelli-Cohen MP, Clémancey M, Martelli A, Riquier S, Guittet E, Latour JM, Puccio H, Drapier JC, et al: The diabetes drug target MitoNEET governs a novel trafficking pathway to rebuild an $\mathrm{Fe}-\mathrm{S}$ cluster into cytosolic aconitase/iron regulatory protein 1 . J Biol Chem 289: 28070-28086, 2014.

13. Todd LR, Damin MN, Gomathinayagam R, Horn SR, Means AR and Sankar U: Growth factor ervl-like modulates Drp1 to preserve mitochondrial dynamics and function in mouse embryonic stem cells. Mol Biol Cell 21: 1225-1236, 2010.

14. Ibrahim S and Weiss TS: Augmenter of liver regeneration: Essential for growth and beyond. Cytokine Growth Factor Rev 45: 65-80, 2019.

15. Zeng HQ, Luo Y, Lou SF, Liu Q, Zhang L and Deng JC: Silencing of augmenter of liver regeneration inhibited cell proliferation and triggered apoptosis in U266 human multiple myeloma cells. Braz J Med Biol Res 50: e6139, 2017.

16. Kim HY, Stojadinovic A and Izadjoo MJ: Immunization, hybridoma generation, and selection for monoclonal antibody production. Methods Mol Biol 1131: 33-45, 2014.

17. Anders S and Huber W: Differential expression analysis for sequence count data. Genome Biol 11: R106, 2010.

18. Franceschini A, Szklarczyk D, Frankild S, Kuhn M, Simonovic M, Roth A,Lin J,MinguezP,Bork P, von Mering C, et al: STRING v9.1: Protein-protein interaction networks, with increased coverage and integration. Nucleic Acids Res 41D: D808-D815, 2013.

19. Chin $\mathrm{CH}$, Chen SH, Wu HH, Ho CW, Ko MT and Lin CY: cytoHubba: Identifying hub objects and sub-networks from complex interactome. BMC Syst Biol 8 (Suppl 4): S11, 2014.

20. Livak KJ and Schmittgen TD: Analysis of relative gene expression data using real-time quantitative PCR and the 2(-Delta Delta C(T)) Method. Methods 25: 402-408, 2001.

21. Vodovotz Y, Prelich J, Lagoa C, Barclay D, Zamora R, Murase N and Gandhi CR: Augmenter of liver regeneration (ALR) is a novel biomarker of hepatocellular stress/inflammation: In vitro, in vivo and in silico studies. Mol Med 18: 1421-1429, 2013.

22. Cao Y,Fu YL, Yu M, Yue PB, Ge CH,Xu WX,Zhan YQ,LiCY,LiW and Wang XH: Human augmenter of liver regeneration is important for hepatoma cell viability and resistance to radiation-induced oxidative stress. Free Radic Biol Med 47: 1057-1066, 2009.

23. Kanehisa M, Furumichi M, Tanabe M, Sato Y and Morishima K: KEGG: New perspectives on genomes, pathways, diseases and drugs. Nucleic Acids Res 45D: D353-D361, 2017.

24. Sun Y, Liu WZ, Liu T, Feng X, Yang N and Zhou HF: Signaling pathway of MAPK/ERK in cell proliferation, differentiation, migration, senescence and apoptosis. J Recept Signal Transduct Res 35: 600-604, 2015.

25. Giorda R, Hagiya M, Seki T, Shimonishi M, Sakai H, Michaelson J, Francavilla A, Starzl TE and Trucco M: Analysis of the structure and expression of the augmenter of liver regeneration (ALR) gene. Mol Med 2: 97-108, 1996.

26. Yu HY, Xiang DR, Huang HJ, Li J and Sheng JF: Expression level of augmenter of liver regeneration in patients with hepatic failure and hepatocellular carcinoma. Hepatobiliary Pancreat Dis Int 9: 492-498, 2010. 
27. Gatzidou E, Mantzourani M, Giaginis C, Giagini A, Patsouris E, Kouraklis G and Theocharis S: Augmenter of liver regeneration gene expression in human colon cancer cell lines and clinical tissue samples. J BUON 20: 84-91, 2015.

28. Shen Y, Liu Q, Sun H, Li X, Wang N and Guo H: Protective effect of augmenter of liver regeneration on vincristine-induced cell death in Jurkat T leukemia cells. Int Immunopharmacol 17: 162-167, 2013.

29. Polimeno L, Pesetti B, Lisowsky T, Iannone F, Resta L, Giorgio F, Mallamaci R, Buttiglione M, Santovito D, Vitiello F, et al: Protective effect of augmenter of liver regeneration on hydrogen peroxide-induced apoptosis in SH-SY5Y human neuroblastoma cells. Free Radic Res 43: 865-875, 2009.

30. Polimeno L, Pesetti B, De Santis F, Resta L, Rossi R, De Palma A, Girardi B, Amoruso A and Francavilla A: Decreased expression of the augmenter of liver regeneration results in increased apoptosis and oxidative damage in human-derived glioma cells Cell Death Dis 3: e289, 2012

31. Zhang LM, Liu DW, Liu JB, Zhang XL, Wang XB, Tang LM and Wang LQ: Effect of naked eukaryotic expression plasmic encoding rat augmenter of liver regeneration on acute hepatic injury and hepatic failure in rats. World J Gastroenterol 11 3680-3685, 2005

32. Ilowski M, Kleespies A, de Toni EN, Donabauer B, Jauch KW, Hengstler JG and Thasler WE: Augmenter of liver regeneration (ALR) protects human hepatocytes against apoptosis. Biochem Biophys Res Commun 404: 148-152, 2011.

33. Dayoub R, Thasler WE, Bosserhoff AK, Singer T, Jauch KW, Schlitt HJ and Weiss TS: Regulation of polyamine synthesis in human hepatocytes by hepatotrophic factor augmenter of liver regeneration. Biochem Biophys Res Commun 345: 181-187, 2006.

34. Polimeno L, Pesetti B, Annoscia E, Giorgio F, Francavilla R, Lisowsky T, Gentile A, Rossi R, Bucci A and Francavilla A: Alrp, a survival factor that controls the apoptotic process of regenerating liver after partial hepatectomy in rats. Free Radic Res 45: 534-549, 2011.

35. Liao XH,Zhang L, Liu Q, Sun H,Peng CM and Guo H: Augmenter of liver regeneration protects kidneys from ischaemia/reperfusion injury in rats. Nephrol Dial Transplant 25: 2921-2929, 2010

36. Liao XH, Chen GT, Li Y, Zhang L, Liu Q, Sun H and Guo H: Augmenter of liver regeneration attenuates tubular cell apoptosis in acute kidney injury in rats: The possible mechanisms. Ren Fail 34: 590-599, 2012.

37. Wang N, Sun H, Shen Y, Li XF, Pan T, Liu GL and Liu Q Augmenter of liver regeneration inhibits apoptosis of activated human peripheral blood lymphocytes in vitro. Immunopharmacol Immunotoxicol 35: 257-263, 2013.

38. Francavilla A, Vujanovic NL, Polimeno L, Azzarone A, Iacobellis A, Deleo A, Hagiya M, Whiteside TL and Starzl TE: The in vivo effect of hepatotrophic factors augmenter of liver regeneration, hepatocyte growth factor, and insulin-like growth factor-II on liver natural killer cell functions. Hepatology 25 411-415, 1997.

39. Weiss TS, Lupke M, Ibrahim S, Buechler C, Lorenz J, Ruemmele P, Hofmann U, Melter M and Dayoub R: Attenuated lipotoxicity and apoptosis is linked to exogenous and endogenous augmenter of liver regeneration by different pathways. Plos One 12: e0184282, 2017.
40. Huang TC, Chiu PR, Chang WT, Hsieh BS, Huang YC, Cheng HL, Huang LW, Hu YC and Chang KL: Epirubicin induces apoptosis in osteoblasts through death-receptor and mitochondrial pathways. Apoptosis 23: 226-236, 2018.

41. Li Y, Li M, Xing G, Hu Z, Wang Q, Dong C, Wei H, Fan G, Chen J, Yang X, et al: Stimulation of the mitogen-activated protein kinase cascade and tyrosine phosphorylation of the epidermal growth factor receptor by hepatopoietin. J Biol Chem 275: 37443-37447, 2000

42. Zhu J, Bing C and Wilding JPH: $1 \alpha, 25(\mathrm{OH}) 2 \mathrm{D} 3$ attenuates IL-6 and IL-1 $\beta$-mediated inflammatory responses in macrophage conditioned medium-stimulated human white preadipocytes by modulating $\mathrm{p} 44 / 42$ MAPK and NF- $\mathrm{BB}$ signaling pathways. Diabetol Metab Syndr 11: 9, 2019.

43. Yu Y, Wei SG, Zhang ZH, Weiss RM and Felder RB: ERK1/2 MAPK signaling in hypothalamic paraventricular nucleus contributes to sympathetic excitation in rats with heart failure after myocardial infarction. Am J Physiol Heart Circ Physiol 310: H732-H739, 2016.

44. von Kriegsheim A, Baiocchi D, Birtwistle M, Sumpton D, Bienvenut W, Morrice N, Yamada K, Lamond A, Kalna G, Orton R, et al: Cell fate decisions are specified by the dynamic ERK interactome. Nat Cell Biol 11: 1458-1464, 2009.

45. Sławińska-Brych A, Zdzisińska B, Czerwonka A, Mizerska-Kowalska M, Dmoszyńska-Graniczka M, Stepulak A and Gagoś M: Xanthohumol exhibits anti-myeloma activity in vitro through inhibition of cell proliferation, induction of apoptosis via the ERK and JNK-dependent mechanism, and suppression of sIL-6R and VEGF production. Biochim Biophys Acta, Gen Subj 1863: 129408: 2019.

46. Park S, Lee HJ, Jeong SJ, Song HS, Kim M, Lee HJ, Lee EO, Kim DH, Ahn KS and Kim SH: Inhibition of JAK1/STAT3 signaling mediates compound $\mathrm{K}$-induced apoptosis in human multiple myeloma U266 cells. Food Chem Toxicol 49: 1367-1372, 2011.

47. Dayoub R, Buerger L, Ibrahim S, Melter M and Weiss TS: Augmenter of liver regeneration (ALR) exhibits a dual signaling impact on hepatic acute-phase response. Exp Mol Pathol 102: 428-433, 2017.

48. Teng EC, Todd LR, Ribar TJ, Lento W, Dimascio L, Means AR and Sankar U: Gfer inhibits Jab1-mediated degradation of p27kip1 to restrict proliferation of hematopoietic stem cells. Mol Biol Cell 22: 1312-1320, 2011.

49. Yang J, Chen L, Yan Y, Qiu J, Chen J, Song J, Rao Q, Ben-David Y, Li Y and Hao X: BW18, a C-21 steroidal glycoside, exerts an excellent anti-leukemia activity through inducing $\mathrm{S}$ phase cell cycle arrest and apoptosis via MAPK pathway in K562 cells. Biomed Pharmacother 112: 108603, 2019.

This work is licensed under a Creative Commons Attribution-NonCommercial-NoDerivatives 4.0 International (CC BY-NC-ND 4.0) License. 